OPEN ACCESS

Edited by:

Lyne Morissette,

M - Expertise Marine, Canada

Reviewed by:

Thomas A. Jefferson,

Clymene Enterprises, United States

Benjamin de Montgolfier,

Consultant, Sainte-Luce, Martinique

*Correspondence:

Lotfi Rabaou

Irabaoui@gmail.com;

Irabaoui@kfupm.edu.sa

Specialty section:

This article was submitted to

Marine Megafauna,

a section of the journal

Frontiers in Marine Science

Received: 29 March 2021

Accepted: 13 July 2021

Published: 03 August 2021

Citation:

Rabaoui L, Roa-Ureta $R H$,

Yacoubi L, Lin Y-J, Maneja R, Joydas TV, Panickan P, Gopalan J,

Loughland $R$, Prihartato $P K$

Qassem A, Hikmawan TI,

Diaz Lopez B and Qurban MA (2021)

Diversity, Distribution, and Density

of Marine Mammals Along the Saudi

Waters of the Arabian Gulf: Update

From a Multi-Method Approach.

Front. Mar. Sci. 8:687445.

doi: 10.3389/fmars.2021.687445

\section{Diversity, Distribution, and Density of Marine Mammals Along the Saudi Waters of the Arabian Gulf: Update From a Multi-Method Approach}

\author{
Lotfi Rabaoui" ${ }^{*}$, Ruben H. Roa-Ureta ${ }^{2}$, Lamia Yacoubi ${ }^{3}$, Yu-Jia Lin', Rommel Maneja1, \\ Thadickal V. Joydas', Premlal Panickan', Jinoy Gopalan', Ronald Loughland", \\ Perdana K. Prihartato4, Ali Qassem ${ }^{4}$, Tyas I. Hikmawan ${ }^{4}$, Bruno Diaz Lopez $^{5}$ and \\ Mohammed A. Qurban ${ }^{1,6}$ \\ ${ }^{1}$ Center for Environment and Marine Studies, Research Institute, King Fahd University of Petroleum \& Minerals, Dhahran, \\ Saudi Arabia, ${ }^{2}$ Centre of Marine Science (CCMAR), University of Algarve, Faro, Portugal, ${ }^{3}$ University of Carthage, Tunis, \\ Tunisia, ${ }^{4}$ Environmental Protection Department, Saudi Aramco, Dhahran, Saudi Arabia, ${ }^{5}$ The Bottlenose Dolphin Research \\ Institute BDRI, Pontevedra, Spain, ${ }^{6}$ Deputy-Ministry for Environment, Ministry of Environment, Water and Agriculture, \\ Riyadh, Saudi Arabia
}

Despite the important role of marine mammals in marine ecosystems and the imperative for their conservation, there is still a great lack of information on the diversity, distribution, and density of these animals in the Saudi waters of the Arabian Gulf. To fill this gap, an integrative data-collection approach including fishermen's questionnaires, opportunistic sighting reports, and directed boat-based surveys, was undertaken between 2016 and 2020, leading to the first scientific report of marine mammal diversity, distribution, and density in the region. The results of the different approaches carried out during the study confirmed a high diversity of cetaceans on the west coast of the study area, with bottlenose dolphins (Tursiops aduncus), humpback dolphins (Sousa plumbea) and dugongs (Dugong dugon) as the most common species. While the two dolphin species were found to be widely distributed in both coastal and offshore waters, D. dugon appears to occur exclusively in coastal waters in the southern part of the study area, mainly in the Gulf of Salwah. The presence of both species of dolphins increased during the summer months and in the vicinity of the numerous oil and gas facilities in this region. The distribution of the observed dolphins was found mostly within a 10-20 km radius around each facility. Other cetacean species observed less frequently in the area include Bryde's whale (Balaenoptera edeni), killer whale (Orcinus orca), common dolphin (Delphinus delphis) and finless porpoise (Neophocaena phocaenoides). Regarding the density of marine mammals in the region, boat-based surveys confirmed the results of fishermen's questionnaires and reports of opportunistic sightings, with bottlenose and humpback dolphins being the most abundant species. These results provide a baseline for policies oriented to the conservation of mammals in the Saudi waters of the Arabian Gulf.

Keywords: cetaceans, marine mammals conservation, Arabian Gulf, dolphins, dugongs, Saudi Arabia 


\section{INTRODUCTION}

Marine mammals represent the most highly developed aquatic animals and form a very important group in marine systems around the world (Bowen, 1997). They are a very varied group characterized by unique physical adaptations that allow them to thrive in the marine environment. From a taxonomic point of view, they are classified in 4 different groups: cetaceans, pinnipeds, sirenians and marine fissipeds (Hodgson, 2012). All species in these groups (ranging from small sea otters Enhydra lutris to large blue whales Balaenoptera musculus) are important consumers at different levels of the marine food web (Frazier et al., 1984; Díaz López et al., 2008; Giralt Paradell et al., 2019). We can find animals that feed on primary production (sirenians) as well as predators of fish and even other marine mammals, as in the case of killer whales Orcinus orca, some pinnipeds and the polar bear Ursus maritimus (Katona and Whitehead, 1988). Because of their trophic position and biomass, they are believed to have a major influence on the structure and function of marine communities (Estes, 1979; Ray, 1981; Laws, 1984; Bowen, 1997). Several studies confirm the role of keystone species of several marine mammals. For example, sea otters strongly affect kelp forest communities through predation on sea urchins, gray whales Eschrichtius robustus and walrus Odobenus rosmarus can affect the structure of benthic invertebrate communities, and dugongs Dugong dugon can cultivate the seagrass community on which they feed (Bowen, 1997). Moreover, several marine mammals have also been described as sentinels of coastal ecosystems (Aguirre and Tabor, 2004), including sea otters (Jessup et al., 2004), bottlenose dolphins (Tursiops aduncus and Tursiops truncatus; Wells et al., 2004; Díaz López et al., 2008; Díaz López, 2020) and manatees (Trichechus spp.) (Bonde et al., 2004).

Despite the important role of marine mammals in marine ecosystems and the imperative for their conservation, there is still a great lack of information on the diversity, distribution, density, and abundance of these animals in the Arabian Gulf (Baldwin et al., 2004; Preen, 2004; Díaz López et al., 2018; Hemami et al., 2018). The few studies conducted so far on marine mammals in Saudi waters focused mainly on the important presence of dugongs in the Gulf of Salwah, at the border with Qatar, Bahrain and United Arab Emirates, where they feed on shallow coastal seagrass beds, and which are threatened by the multiple anthropogenic activities concentrated along this coast. While no specific studies have been carried out, the presence of other marine mammal species was cited in this region. These include Indo-Pacific bottlenose dolphins (Tursiops aduncus), Indian Ocean humpback dolphins (Sousa plumbea), finless porpoises (Neophocaena phocaenoides), common dolphins (Delphinus delphis), striped dolphins (Stenella coeruleoalba), Risso's dolphins (Grampus griseus) and spotted dolphins (Stenella attenuata) (Hodgson, 2012). In addition, at least 10 species of whales were listed in Saudi Arabia's National Biodiversity Strategy Action Plan (NBSAP) for Saudi waters. These include Bryde's, humpback, minke, fin and blue whales, killer and false killer whales (Lindén et al., 2004).

Despite the various records of marine mammals in the region, there remains a large knowledge gap on their spatiotemporal distribution and density, which is a major impediment to their conservation. In this context, the present work was carried out to achieve the following objectives: (i) to determine the distribution and density of the different species of marine mammals present in the Saudi Arabian Gulf waters, and (ii) to characterize the ecological traits of these animals, paying special attention to the effect of environmental factors on their distribution in this area.

\section{MATERIALS AND METHODS}

To achieve the goals of this work, four different methodologies were adopted. These include: fishermen's questionnaires, opportunistic sighting records, and boat-based surveys.

\section{Fishermen's Questionnaires}

Over two thousand artisanal fishing boats operate year-round in Saudi waters of the Arabian Gulf (Roa-Ureta, 2015). These people spend one of the largest amounts of time at sea in the region and sometimes they capture mammals as by-catch. Although their observations lack any systematicity and can be duplicates, rendering them inadequate to estimate density or abundance, they have the utility of connecting the frequency of observations with covariables such as time of the year and location characteristics in linear regressions. Thus a standard questionnaire form was generated for this study (Supplementary Figure 1). The questionnaire consists of 18 questions covering the maximum amount of information that need to be collected about the interviewees, their fishing experience, target species, fishing gear and seasons; but also about the observation, and/or incidental capture of marine mammals, time and place of observation, and/or capture and the number of individuals observed/captured. Regarding the observation/bycatch of marine mammals, a maximum time scale of the last two months (for dolphins) or 6 months (for whales, killer whales, and dugongs) was considered. To locate cetacean sighting records, fishermen were asked to place their sightings in one of 14 boxes on a grid dividing Saudi territorial waters in the Gulf (Supplementary Figure 2). To avoid any repetition, only boat captains were interviewed. During the interview, fishermen were provided with an identification guide (Supplementary Figure 3) to ensure their ability to distinguish between four groups: dolphins, dugongs, baleen whales, and orcas. Some of the fishermen reported the species identification of some dolphin species (mainly humpback dolphins, bottlenose dolphins, and finless porpoises). The ability of these latter fishermen to distinguish between species was checked by showing them videos and photos of dolphins' sightings previously reported by the interviewing team. If the interviewed fisherman showed some ambiguity in identifying the species shown on the videos or photos, we consider the dolphin sighted as unidentified. The data collected through the fishermen's questionnaires were used to test two types of hypotheses using generalized linear models (GLM):

- In the first hypothesis, we tested whether the presence of a sighting for each of the marine mammal types (dolphins, whales, dugongs, and killer whales), depended 
on the number of oil and gas installations in each reported spatial box, the season of the sighting (warm season: May to October, cold season: November to April) and the presence of other types of marine mammals. In these models, the data distribution was binomial and the link function was the logit.

- The second hypothesis test concerned group size during a sighting for each of the selected marine mammal types. In this test, the questions of the dependence of the number of oil and gas installations on the stated spatial box of the sighting, the period of the year in which the sighting occurred, and the size of groups of other types of marine mammals were tested. In these models, the data distribution was Poisson and the link function was the logarithm.

\section{Opportunistic Sighting Records}

The aim of this work was to compile marine mammal sighting records reported by marine scientists from the Center for

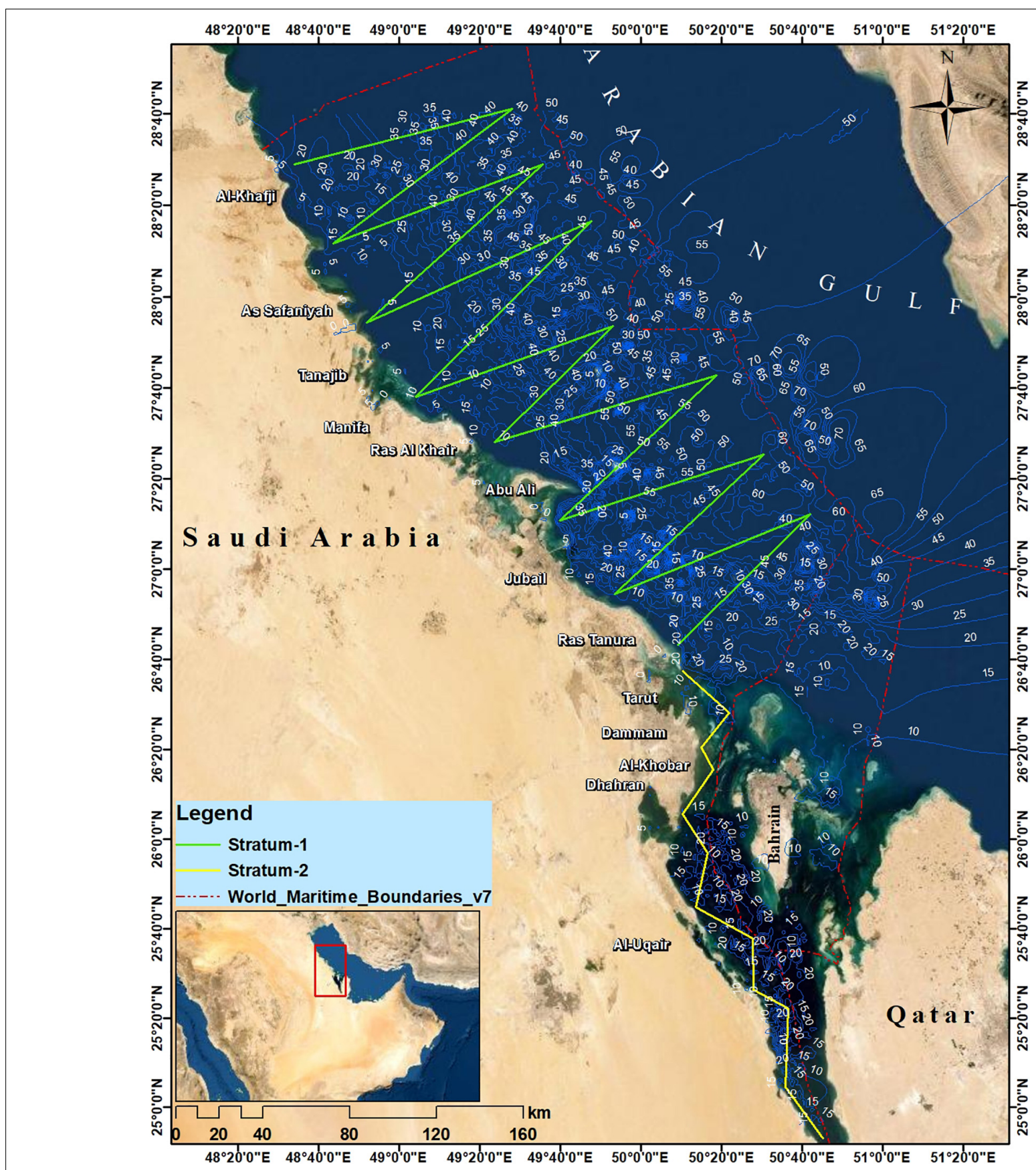

FIGURE 1 | Transects covered during the boat-based surveys conducted in Springs 2018 and 2019 
Environment \& Marine Studies (King Fahd University of Petroleum \& Minerals, Dhahran, Saudi Arabia) who have to perform daily duties in the Saudi waters of the Arabian Gulf, in relation to other projects. For this purpose, a "sighting record" form was prepared and distributed to all these observers. For each marine mammal opportunistic sighting report, the observer has to note: the time and date, the location of the sighting, the type of marine mammal observed (dolphin, whale, dugong, killer whale), the number of juveniles and adults observed, the behavior and the direction of travel of the observed animals (Supplementary Figure 4). Observers were also asked to take photos and/or videos and, if possible, try to identify the species based on the identification guide that accompanied the sighting record form (Supplementary Figure 3). The survey began in February 2016 and lasted until October 2020.

The data analysis was restricted to dolphins only, the group that has amassed a sufficient amount of sightings to be analyzed. The analysis consists of investigating the connection between the number of sightings and the size of the groups and depth on one hand and the presence of oil and gas facilities (O\&G) on the other. With this analysis we are asking whether the groups of dolphins are attracted or repelled by the proximity to O\&G or whether they have a neutral distribution with respect to $O \& G$. This is because we have found earlier that $O \& G$ are locations of concentration of fish (Rabaoui et al., 2015) which could be prey to dolphins. In addition, we wanted to determine the home range of dolphins with respect to $O \& G$ by analyzing the effect of different distances. Thus for each sighting we counted the number of O\&G within a $5 \mathrm{~km}$ radius of the sighting, 10,20, and $50 \mathrm{~km}$ radius.

A further question that we asked from the data was whether the results of the analyses above changed when the groups of dolphins were observed without calves. To conduct this test, we repeated the analyses described above but only for the subset of observations of dolphin groups without calves.

The models fitted were generalized linear models with the Poisson distribution and the logarithmic link, which is
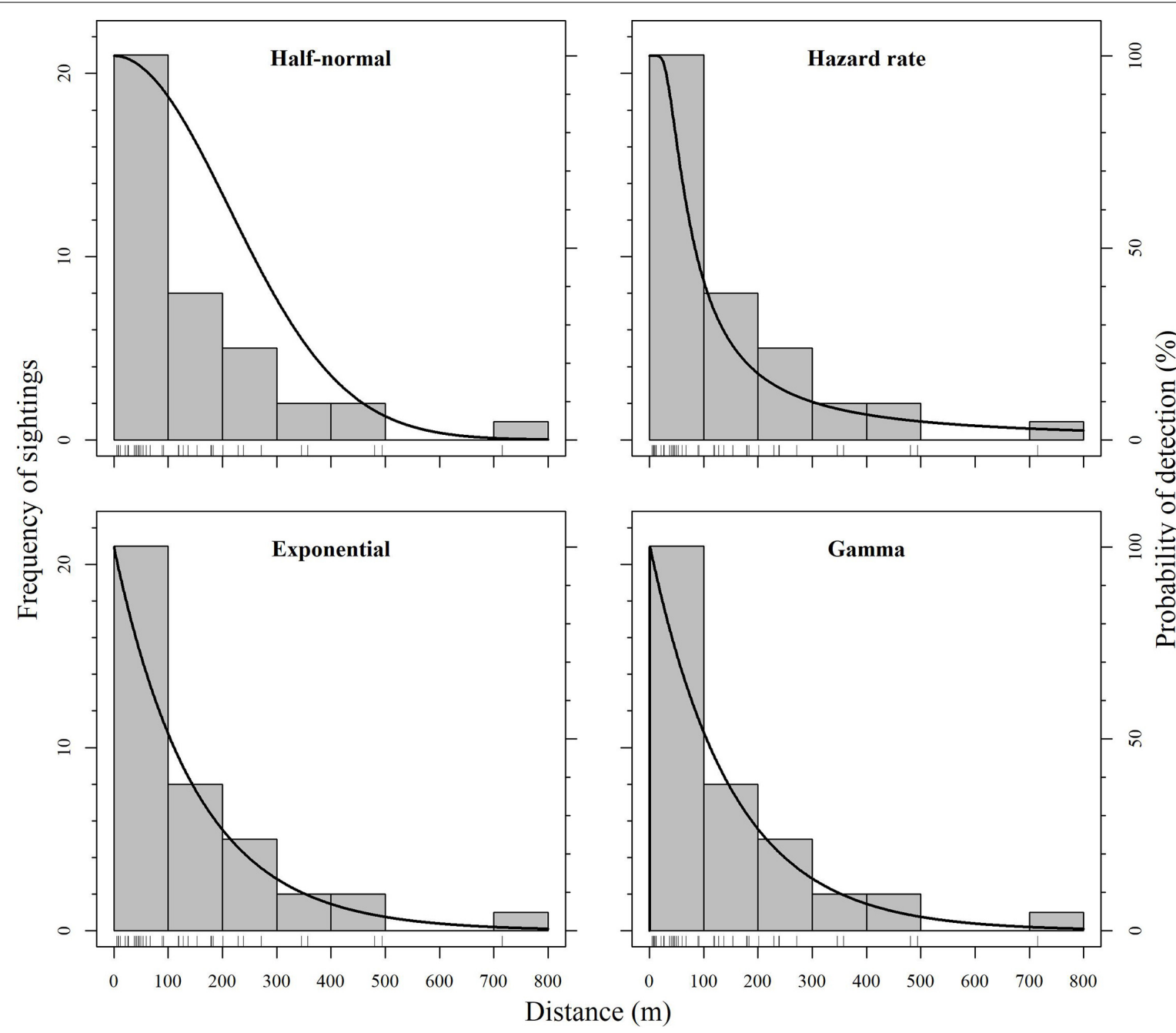

FIGURE 2 | Histogram of detection at increasing distance (gray bars, observed data are represented by the small bars on the $\mathrm{x}$-axis) and fitted detection function (solid line) for the four density function models (half-normal, hazard rate, negative exponential, and gamma). 
statistically appropriate for counts data. To test hypotheses for the effect of depth and the size of the home range in relation to the number of O\&G, we fitted the following models to both, all the sighting counts of dolphin groups and the subset of sighting counts of dolphin groups without calves ( $G$ represents $O \& G)$ :

$$
\begin{aligned}
& \text { Null model : } \log (y)=\beta_{0} \\
& \log (y)=\beta_{0}+\beta_{D} D \\
& \log (y)=\beta_{0}+\beta_{D} D+\beta_{5 k m} G 5 k m \\
& \log (y)=\beta_{0}+\beta_{D} D+\beta_{5 k m} G 5 k m+\beta_{10 k m} G 10 k m \\
& \log (y)=\beta_{0}+\beta_{D} D+\beta_{5 k m} G 5 k m+\beta_{10 k m} G 10 k m \\
& +\beta_{20 k m} G 20 k m \\
& \log (y)=\beta_{0}+\beta_{D} D+\beta_{5 k m} G 5 k m+\beta_{10 k m} G 10 k m \\
& +\beta_{20 k m} G 20 k m+\beta_{50 k m} G 50 k m \\
& \log (y)=\beta_{0}+\beta_{D} D+\beta_{5 k m} G 5 k m+\beta_{10 k m} G 10 k m \\
& +\beta_{50 k m} G 50 k m \\
& \log (y)=\beta_{0}+\beta_{D} D+\beta_{5 k m} G 5 k m+\beta_{50 k m} G 50 k m
\end{aligned}
$$

Subsequently we determined the best working model by selecting the hypothesis with the lowest Akaike Information Criterion (AIC). Finally, we presented the table of coefficients (the $\beta$ s in the equations above) for the best model to interpret the effect of depth and whether there is attraction or repulsion to O\&G and what is the home range connected to those effects.

TABLE 1 | Best supported model (in bold) for observations of dolphins, dugong and whales by fishermen as absence/presence data and as group size conditions on presence.

\begin{tabular}{llcc}
\hline Cetacean group & Model & AIC presence & AIC group size \\
\hline Dolphins & Null & 573.3 & 3110.8 \\
& Season & 575.3 & $\mathbf{2 9 8 4 . 8}$ \\
& Season+O\&G & $\mathbf{6 . 0}$ & 2986.7 \\
& Season+O\&G+Dugongs & 8.1 & 2987.5 \\
& Season+O\&G+Dugongs & 10.0 & 2987.5 \\
& +Whales & & \\
& Season+O\&G+Dugongs & 12.0 & 2988.6 \\
& +Whales+Killer Whales & & \\
& Season+O\&G+Dugongs & 10.1 & 2988.6 \\
& +Killer Whales & & \\
Dugongs & Null & $\mathbf{2 1 8 . 7}$ & $\mathbf{8 3 . 6}$ \\
& Season & 220.7 & 85.6 \\
Whales & Null & 319.8 & 102.5 \\
& Season & 317.9 & 103.5 \\
& Season+WhalOgf & $\mathbf{1 0 4 . 7}$ & $\mathbf{1 0 1 . 8}$ \\
& Season+WhalOgf+DugSig & 105.4 & 103.7 \\
& Season+WhalOgf+DugSig & 106.9 & 105.6 \\
& +DolSig & & \\
& Season+WhalOgf+DugSig & 108.6 & 105.6 \\
& +DolSig+KillSig & & \\
& Season+WhalOgf+DugSig & 107.1 & 103.7 \\
& +KillSig & & \\
& & & \\
& & &
\end{tabular}

\section{Boat-Based Surveys}

The goal of this fieldwork is to have estimates on the density of the most common cetacean species occurring in the Saudi waters of the Gulf. The design of the boat-based survey was adopted following the methodology described in Thomas et al. (2007). The territorial Saudi waters in the Gulf were divided into 2 strata: stratum 1 covering the northern and central waters and stratum 2 covering the southern waters. Equal-spaced zig-zag and parallel transects were defined in stratums 1 and 2, respectively (Figure 1). The start points of all these transects were randomly placed in order to allow an equal coverage probability within each stratum (Williams and Thomas, 2007). Two complete surveys were completed between March 2018 and March 2019 using the SELBAR boat (17.6- $\mathrm{m}$ long fiberglass boat). During the searching effort, the boat traveled, during calm weather conditions (wind speed $<7$ knots), at a speed of approximately 8 knots $(\sim 15 \mathrm{~km}$ $h^{-1}$ ). The team onboard of the boat consisted of three observers experienced in marine mammals visual surveys and species identification in the Arabian Gulf: two primary observers and one data recorder. The two primary observers were positioned on the highest accessible point of the boat platform ( $\sim 6 \mathrm{~m}$ height), and were responsible on searching cetaceans, with naked eyes, on the visual fields extending from dead ahead (0o) to $90 \circ$ toward the port or starboard sides of the boat, depending on the observer position. Whenever a sighting was made, the data recorder noted all the sighting information and assisted, if needed, the two primary observers in the identification of the observed species and estimating the school size. The sighting distance was estimated visually, after extensive training of the observers using a HAWKE laser rangefinder (tested accuracy $\pm 1 \mathrm{~m}$ from 10 to $900 \mathrm{~m}$ ). Reticle eyepieces and compass-equipped binoculars were used to estimate the sighting angles, and also to confirm the estimated sighting distance and the identification of observed marine mammal species. All observations were made during day time and under calm weather conditions.

Statistical estimation of mammal's density in the Saudi waters of the Gulf was carried out using distance sampling methods with sightings data in the Rdistance package (McDonald et al., 2019) of the R statistical system (R Core Team, 2019). Dugongs were not observed in sufficient quantities (2 individuals in one site) for a separate estimation of their density. Because of the limited number of observations, the dolphin sightings collected for the

TABLE 2 | Coefficients of the best supported model for observations of whales by fishermen as absence/presence data and as group size conditions on presence.

\begin{tabular}{lccc}
\hline Predictor & Coefficient & Std. Error & $p$ value \\
\hline Absence/presence & & & \\
Intercept & -3.292 & 0.322 & $<0.0001$ \\
Season (hot) & -1.960 & 1.053 & 0.0627 \\
O\&G & 10.980 & 880.427 & 0.9901 \\
Number conditional on presence & & \\
Intercept & -0.612 & 0.282 & 0.0299 \\
Season (hot) & 0.293 & 0.330 & 0.3751 \\
O\&G & 0.018 & 0.009 & 0.0523
\end{tabular}


two dolphin species (S. plumbea and T. aduncus) and for the two surveys were pooled and used in the analysis.

In distance sampling, it is necessary to estimate a detection function because not all individuals are observed within the range of visibility and individuals that are closer to the observation site are more likely to be observed than individuals located far across the visibility range. In this work, we carried out the estimation of density considering detection functions of four kinds: half normal, hazard rate, negative exponential, and Gamma. After estimation of density, the most reliable of these functions was selected on the basis of the Akaike Information Criterion (AIC). The uncertainty of the density estimates was evaluated by using bootstrap with 10,000 iterations. The fit of detection function was also examined visually by plotting the fitted curve with observed detection data (Figure 2).

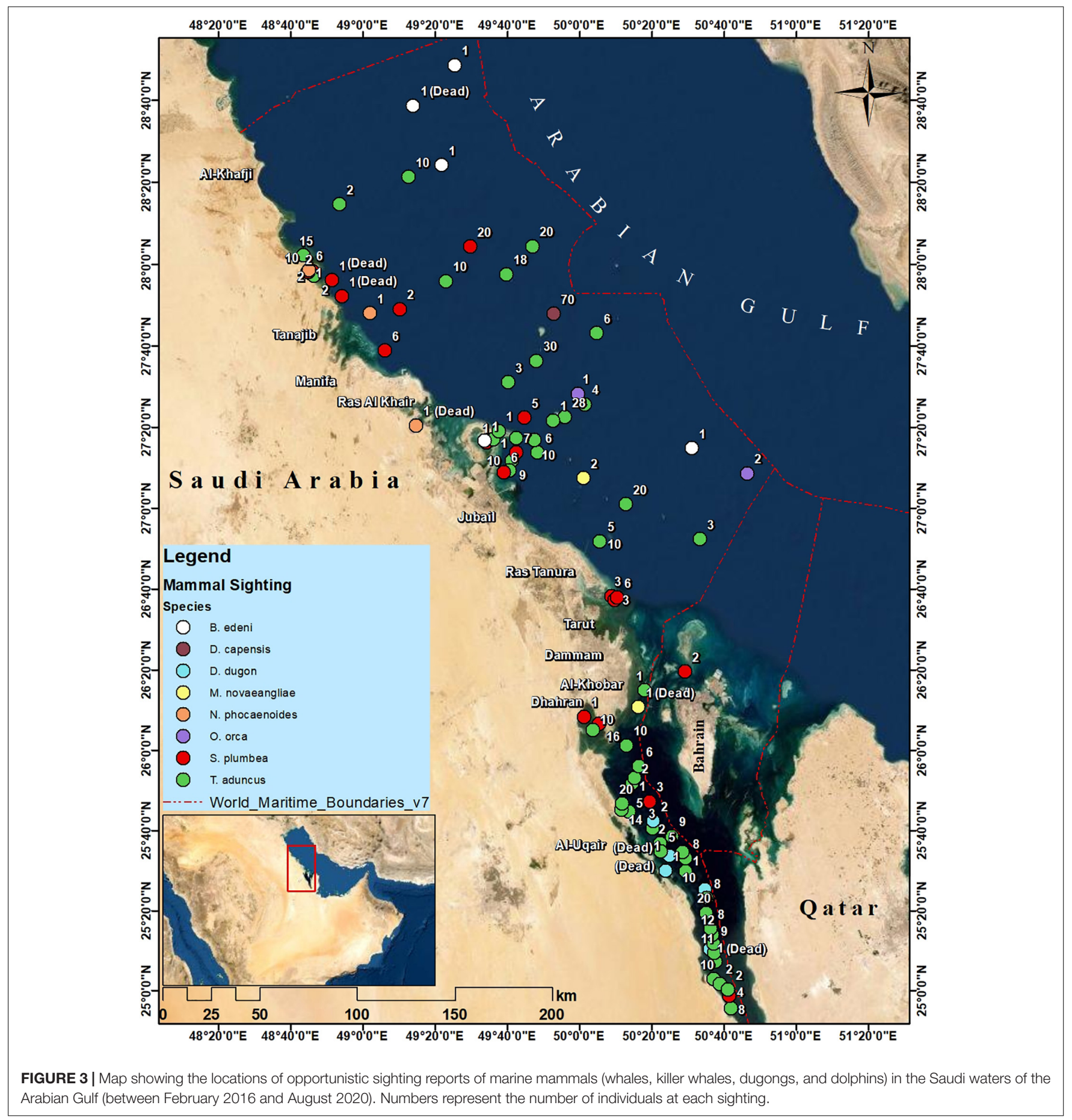




\section{RESULTS}

\section{Fishermen's Questionnaires}

In total, 508 questionnaire forms were filled between January 2017 and January 2019, and the descriptive results are presented in Supplementary Table 1. Supplementary Figure 5 ( $a$ and b) shows the actual counts of oil and gas installations, including offloading units, clusters, Gas/Oil Separation Plants (GOSPs), and wells, per spatial cell.

In total, 381 dolphin sightings were recorded. Most of these dolphin sightings were observed between the months of MarchApril 2017, January-March 2018 and August-December 2018 (Supplementary Figure 6). In a high percentage of the dolphin sightings made by fishermen, the species could not be identified (using the identification guides provided by the interviewers). In the sightings where the dolphin species could be identified, most of the records were for Indo-Pacific bottlenose dolphins (Tursiops aduncus), followed by humpbacks (Sousa plumbea), finless porpoises (Neophocaena phocaenoides) and common dolphins (Delphinus delphis) (Supplementary Figure 6). Regarding the spatial distribution of dolphin sightings, a peak was recorded in boxes 5, 9, and 13, and most sightings were of groups with less than 5 dolphins (Supplementary Figure 7). In the case of dugongs, only 27 sightings were recorded; most of them during March-April 2017 and October 2018. Notably, all dugong sightings were recorded in the southernmost Saudi waters of the Gulf (Gulf of Salwah, spatial bin 13). Most of the sightings corresponded to groups of 2 dugongs (Supplementary Figure 8). As for whales and killer whales (Orcinus orca), their total numbers of sightings were 36 and 7, respectively. Most of these sightings were solitary and were recorded during the cold season (November-April). The highest numbers of sightings for both groups of cetaceans were recorded in boxes 9 and 12 (Supplementary Figure 9).

The model that is best supported by dolphin presence/absence data shows season and number of oil and gas installations as the only predictors (Table 1). Despite this, the statistical precision of the estimates from this model was very low (Table 1). When studying group size conditional on presence, the best supported model is a model conditional only on season of the year (Table 1). This model has a coefficient for season of 0.365 (standard error $=0.023, p$-value $<0.0001$ ), showing a strong tendency to observe more dolphins in the warm season (May to October). In the case of dugong observations, they were only reported in spatial bin 13 (Supplementary Figure 2), so the only possible test with these data refers to the season. For both presence and group size, the null model is best supported by the data (Table 1). Therefore, dugongs are observed equally across seasons only in spatial bin 13. Finally, for whale watching, both for presence/absence data and for counts of individuals in the case of presence, the best supported model includes the season of the year and the number of oil and gas installations in each spatial cell (Table 1). Examination of the coefficients of the best-supported model in Table 2 shows that all results are weak and with large statistical uncertainty. Therefore, no firm conclusions can be drawn from these data on the distribution of observed whales.

\section{Opportunistic Sighting Records}

Between February 2018 and October 2020, a total of 678 mammals were observed in 94 recorded sightings (mean group size 7.2, mean group size 1) (Supplementary Table 2). The majority of these were bottlenose dolphins (53 sightings), followed by humpback dolphins (20 sightings). The common dolphin (D. delphis) was observed only once, but in a very large group (Supplementary Table 2). Supplementary Figures 10-14 represent all cetacean species recorded, during this survey, in Saudi Arabian Gulf waters. The map in Figure 3 shows the location of all records of opportunistic sightings reported during this study.

When considering all marine mammal observations together, group size was related to all factors included in model 6, with

TABLE 3 | Best supported model (in bold) for the relation between all mammals and all dolphins group size and depth and number of oil and gas facilities within 5 , 10,20 , and $50 \mathrm{~km}$ radius.

\begin{tabular}{llc}
\hline Group & Model & AIC \\
\hline All mammals & Null & 1025.5 \\
& Depth & 1018.7 \\
& Depth+OG5km & 1020.1 \\
& Depth+OG5km+OG10km & 1022.1 \\
& Depth+OG5km+OG10km+OG20km & 1022.5 \\
& Depth+OG5km+OG10km+OG20km+OG50km & $\mathbf{9 6 8 . 0}$ \\
& Depth+OG5km+OG10km+OG50km & 978.3 \\
& Depth+OG5km+OG50km & 998.1 \\
& OG5km+OG50km & 999.2 \\
All dolphins & Null & 870.7 \\
& Depth & 836.9 \\
& Depth+N.O\&G.5KM & 837.2 \\
& Depth+N.O\&G.5KM+OG10km & 838.1 \\
& Depth+N.O\&G.5KM+OG10km+OG20km & 839.7 \\
& Depth+N.O\&G.5KM+OG10km+OG20km+OG50km & $\mathbf{7 9 8 . 7}$ \\
& Depth+N.O\&G.5KM+OG10km+OG50km & 810.6 \\
& Depth+N.O\&G.5KM+OG50km & 812.3 \\
& Depth+OG50km & 823.5
\end{tabular}

TABLE 4 | Coefficients of the best supported model for the relation between all mammals and all dolphins group size and depth and number of oil and gas facilities within $5,10,20$, and $50 \mathrm{~km}$ radius.

\begin{tabular}{lcccc}
\hline Group & Factor & Coefficients & Std. error & $\boldsymbol{p}$ value \\
\hline All mammals & Intercept & 1.816 & 0.079 & $<0.001$ \\
& Depth & 0.002 & 0.003 & 0.588 \\
& O\&G.5km & -0.036 & 0.018 & 0.049 \\
& O\&G.10km & 0.040 & 0.011 & $<0.001$ \\
Oll dolphins & O\&G.20km & -0.031 & 0.005 & $<0.001$ \\
& O\&G.50km & 0.007 & 0.001 & $<0.001$ \\
& Intercept & 1.777 & 0.087 & $<0.001$ \\
& Depth & 0.011 & 0.003 & $<0.001$ \\
& O\&G.5km & -0.022 & 0.019 & 0.240 \\
& O\&G.10km & 0.018 & 0.0117 & 0.126 \\
& O\&G.20km & -0.022 & 0.006 & $<0.001$ \\
& O\&G.50km & 0.006 & 0.001 & $<0.001$
\end{tabular}


the lowest AIC (Table 3). Examination of the coefficients of each of the 6 factors (Table 4) reveals that the effect of depth is very weak (and not significant). The strongest effects are those of the number of oil and gas installations within $5 \mathrm{~km}$, which is negative, the number of oil and gas installations within $10 \mathrm{~km}$, which is positive, and the number of oil and gas installations within $20 \mathrm{~km}$, which is again negative. This means that all mammals considered together prefer a home range formed by the ring defined by the juxtaposition of a $10 \mathrm{~km}$ radius circle within a $20 \mathrm{~km}$ radius circle, both centered on each facility (Figure 4).

Focusing on dolphins as the dominant taxonomic group in number, model 6 including all factors is the best supported as indicated by a lowest AIC (Table 3). Examination of the coefficients for each of the 6 factors (Table 4) shows some differences with the model including all mammals together, but also general similarities. The differences are that depth is highly significant with a preference for shallower waters (the interquartile is 8 to $30 \mathrm{~m}$ ) and that the effects of the number of oil and gas installations within the 5 and $10 \mathrm{~km}$ range are not significant, although these are the strongest effects in terms of magnitudes of coefficients. The similarities are in the signs of the coefficients, indicating that dolphins prefer a home range formed by the ring defined by the juxtaposition of a $10 \mathrm{~km}$ radius circle within a $20 \mathrm{~km}$ radius circle, both centered on each facility.

\section{Boat-Based Surveys and Density Estimation}

The bottlenose dolphins were the most observed mammal species with a total of 29 observations and a total count of 231 individuals (Supplementary Table 3), of which 28 were juveniles. The humpback dolphins were encountered less frequently with a total of 10 observations and a total count of 68 individuals, of which 6 were juveniles. These two dolphin species were never observed as solitary individuals with mean group sizes $( \pm \mathrm{SD})$ of $8 \pm 7$ and $7 \pm 3$ per group for bottlenose and humpback dolphins, respectively. The specific location of observations along with the survey transects are shown in Figure 5.

The statistical analysis conducted using the combined data of both dolphin species and both surveys showed that exponential function-based model was the best supported for density estimation, with the lowest AIC. The dolphin density estimated with this model was 0.854 individuals per $\mathrm{km}^{2}$ (coefficient of variation $=53 \%$, with $95 \%$ confidence interval from 0.299 to 2.259, Table 5).

\section{DISCUSSION}

The present study showed the presence of eight cetacean species in the Saudi waters of the Arabian Gulf. These include five species of dolphins (Indo-Pacific bottlenose dolphin: T. aduncus, Indian Ocean humpback dolphin: S. plumbea, finless porpoise: $N$. phocaenoides, common dolphin: D. delphis, and killer whale: O. orca), two species of whales (Bryde's whale: B. edeni and humpback whale: M. novaeangliae) and one species of dugong (D. dugon). The number of species recorded here is almost half of the 17 species recorded in the waters of the Arabian Gulf (including Kuwait, Saudi Arabia, Bahrain, Qatar and the United Arab Emirates) (Carpenter et al., 1997). The failure to observe any of the other species is most likely due to the fact that some cetacean species are

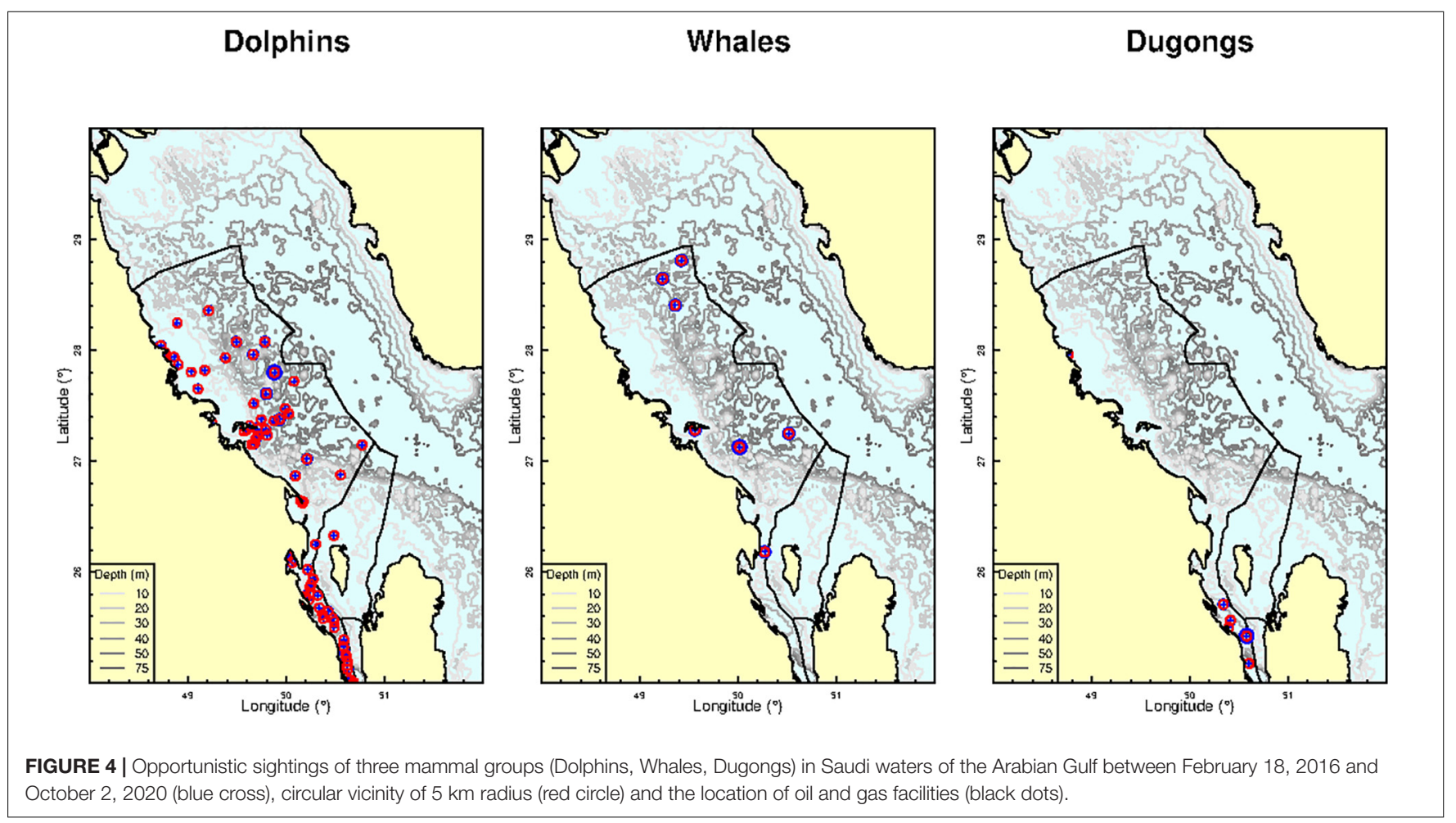


found in the adjacent waters of the Arabian Gulf (Arabian Sea) and that their occurrence is rare or even non-existent in the western Arabian Gulf. The same species encountered during the present study were also recorded in the waters of neighboring countries (Baldwin et al., 2004; Preen, 2004; Al-Abdulrazzak and Pauly, 2017; Díaz López et al., 2018; Hemami et al., 2018), demonstrating that cetacean diversity in the Arabian Gulf is mainly represented by the eight species we recorded. Among these eight species, only three species are commonly present year-round in Saudi Gulf waters. These include the humpback dolphin (S. plumbea), bottlenose dolphin (T. aduncus) and dugong (D. dugon), which were recorded during the systematic boast-based surveys, questionnaire surveys and opportunistic sighting reports. The highest number of species was

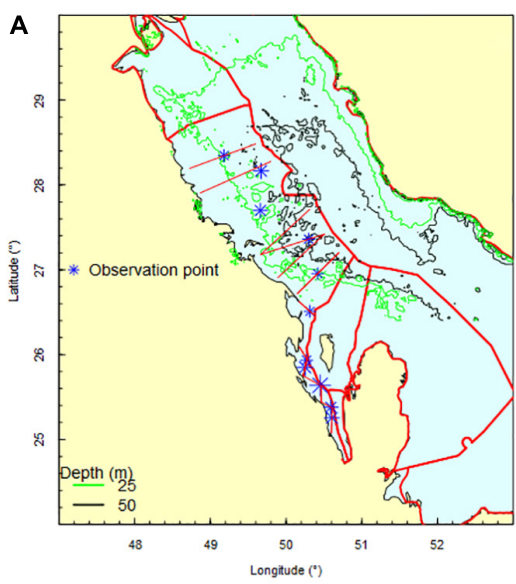

C
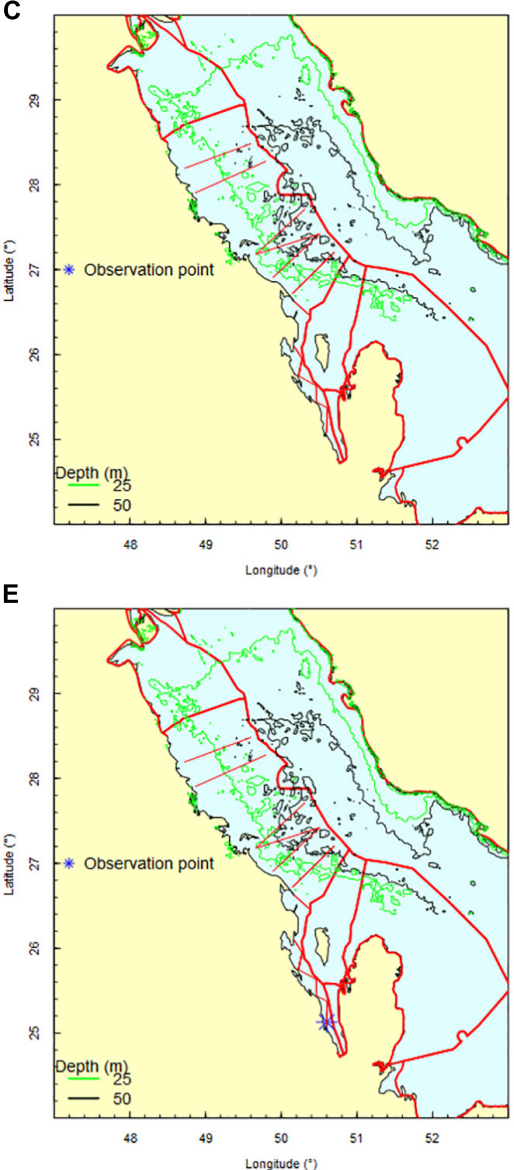

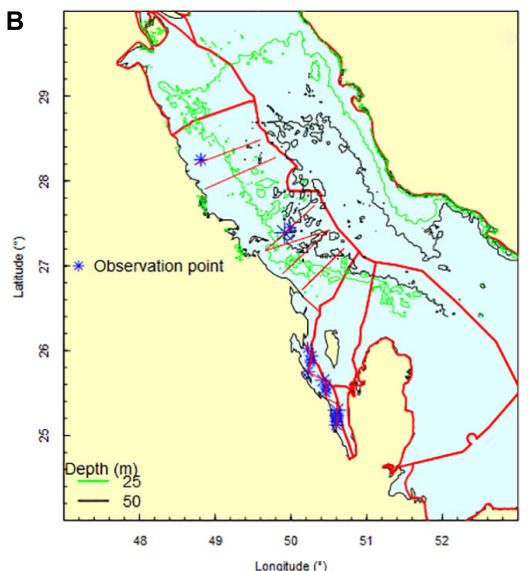

D

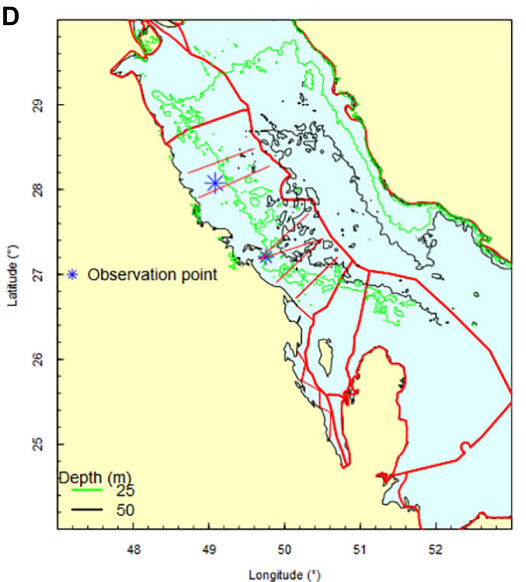

FIGURE 5 | Observation tracks (red straight lines) and observation points (blue asterisk) of bottlenose dolphins (A,B), humpback dolphins (C,D) and dugongs (E) during the two surveys (Spring 2018 and Spring 2019). 
TABLE 5 | Estimate, coefficient of variation (CV) and 95\% confidence interval $(95 \% \mathrm{Cl})$ of the density of dolphins (individuals per square kilometer, sighting data of both bottlenose and humpback dolphins from the two surveys are combined) using distance estimation methods with four density function models.

\begin{tabular}{lcccc}
\hline Model & AIC & Estimate & CV & 95\% Cl \\
\hline Half normal & 476.4 & 0.479 & $45 \%$ & $0.193 \sim 1.116$ \\
Hazard rate & 468.0 & 0.929 & $75 \%$ & $0.282 \sim 3.760$ \\
Exponential & $\mathbf{4 6 7 . 1}$ & $\mathbf{0 . 8 5 4}$ & $\mathbf{5 3 \%}$ & $\mathbf{0 . 2 9 9} \sim \mathbf{2 . 2 5 9}$ \\
Gamma & 468.4 & 0.866 & $46 \%$ & $0.620 \sim 1.943$ \\
\hline
\end{tabular}

Models with best support in each case are marked in bold. The uncertainty in the parameter estimates was assessed using bootstrap with 10,000 iterations.

recorded in the opportunistic sighting reports, demonstrating the usefulness of this technique for recording cetacean biodiversity. This technique also showed that Bryde's whale (B. edeni) and finless porpoise ( $N$. phocaenoides) are also common in the western Arabian Gulf, as they were recorded in different seasons, however, their presence is limited to the northern and offshore areas. According to our direct observations, Bryde's whales come to Saudi waters at certain times of the year to feed on some pelagic fishery resources (see Supplementary Figure 10).

Dolphin density estimate ( $T$. aduncus and $S$. plumbea combined) from the boat surveys ( 0.854 individuals per $\left.\mathrm{km}^{2}\right)$ was within the range of published literature ( 0.22 to 3.4, Table 6), suggesting that the Arabian Gulf is an important area for both bottlenose and humpback dolphins, similarly to other regions of the world. Although, the number of total sightings was low (39, since a minimum of 60 sightings are recommended by Buckland et al., 2001), we believe that the density estimate reported herein is reasonable because the detection function fitted the data well (Figure 2), with density estimate within a reasonably low covariance of variation (53\%). Moreover, the density estimate of the dolphins in the Saudi waters of the Arabian Gulf matches with the values reported from other adjacent and distant areas (Table 6). Future studies using mark-recapture techniques are needed to provide more precise estimates of the status of marine mammal populations and to allow comparison with studies conducted in other areas.

Analysis of opportunistic sighting reports showed the prevalence of dolphins (particularly bottlenose and humpback dolphins) in the study area. Among the environmental factors considered in this study, concentrations of offshore oil and gas structures were found to influence the presence of dolphins in the western Arabian Gulf. In fact, dolphins appeared to prefer a home range formed by the ring defined by the juxtaposition of a $10 \mathrm{~km}$ radius circle within a $20 \mathrm{~km}$ radius circle, both centered on each oil/gas installation. The association between the presence of oil/gas structures and the occurrence of dolphins is probably due to the attraction of dolphins to the fish/shellfish resources associated with these man-made structures. In this regard, Rabaoui et al. (2015) found a higher density of fish and biodiversity at sites with a higher number of oil and gas installations within a $5 \mathrm{~km}$ radius. These associated faunal communities may represent trophic resources for dolphin populations found in Saudi Arabian Gulf waters. However, dolphins also avoid being in close proximity to oil/gas installations, which may be explained by the noise pollution generated by these structures and the navigation of ships around them. Similarly, Todd et al. (2020) demonstrated the close presence of marine megafauna (cetaceans, pinnipeds, sirenians, large fish - such as sharks, rays, billfish, and tuna, as well as marine reptiles and seabirds; many of which are threatened species) to anthropogenic structures, with most animals displaying foraging behavior or interaction with the structures. In this context, various studies reported the occurrence of marine mammals around oil/gas structures (e.g., Cremer et al., 2009; Todd et al., 2009, 2016; Thompson et al., 2010; Delefosse et al., 2018). Other megafauna taxa including sharks, rays and turtles were also reported to occur close these artificial structures (McLean et al., 2017, 2019; Haugen and Papastamatiou, 2019). This proves that many megafaunal species including marine mammals are likely to exploit the trophic resources associated with the marine anthropogenic installations. According to Mackintosh (1974),

TABLE 6 | Comparison of the dolphin density (both bottlenose, T. aduncus, and humpback, S. plumbea, dolphins) in the Saudi waters of the Arabian Gulf with those recorded with the same and other congeneric species in other regions.

\begin{tabular}{|c|c|c|c|c|}
\hline Species & Density (ind. $\mathrm{Km}^{-2}$ ) & Area & Technique & References \\
\hline T. aduncus and S. plumbea & 0.854 & Saudi waters of AG & Boat-Based Surveys & Present work \\
\hline Tursiops truncatus & $\begin{array}{c}1.09 \text { (inshore) }-4.43 \\
\text { (Island) }\end{array}$ & $\begin{array}{l}\text { Mississippi Sound, } \\
\text { United States }\end{array}$ & $\begin{array}{l}\text { Photo-ID capture recapture } \\
\text { technique }\end{array}$ & Mullin et al., 2017 \\
\hline Tursiops truncatus & 0.6 (winter) - 1.3 (summer) & $\begin{array}{l}\text { Mississippi Sound, } \\
\text { United States }\end{array}$ & Boat-Based Surveys & Miller et al., 2013 \\
\hline \multirow[t]{3}{*}{ Sousa plumbea } & 3.40 & Goa Bay, western coast of India & Boat-Based Surveys & Sutaria and Jefferson, 2004 \\
\hline & 0.59 & $\begin{array}{l}\text { Abu Dhabi, United Arab } \\
\text { Emirates }\end{array}$ & $\begin{array}{l}\text { Mark-recapture method of } \\
\text { photo-ID (55 boat based } \\
\text { surveys) }\end{array}$ & Díaz López et al., 2018 \\
\hline & 0.123 & Mousa Bay (Iran) & Boat-Based Survey & Hemami et al., 2018 \\
\hline \multirow[t]{3}{*}{ Sousa chinensis } & 1.36 & $\begin{array}{l}\text { Pearl River Estuary, Southern } \\
\text { China }\end{array}$ & $\begin{array}{l}\text { Boat-Based Surveys } \\
+ \text { Photo-ID }\end{array}$ & Chen et al., 2010 \\
\hline & 0.99 & Zhanjiang Bay, Southern China & $\begin{array}{l}\text { Boat-Based Surveys } \\
+ \text { Photo-ID }\end{array}$ & Xu et al., 2015 \\
\hline & 0.22 & Beibu Bay, Southern China & Boat-Based Surveys & Chen et al., 2009 \\
\hline
\end{tabular}


the interactions of marine mammals with these structures show a direct contact, rather than avoidance behavior. The use of marine structures by large marine animals for feeding purpose was evidenced in several papers (Russell et al., 2014; Arnould et al., 2015; Todd et al., 2016, 2020; Orr et al., 2017; Delefosse et al., 2018).

In the Saudi waters of the Arabian Gulf, oil and gas installations have an exclusion circle around them of $500 \mathrm{~m}$ radius, which fishermen and other unauthorized vessels are prohibited from entering. Therefore, mammals may not have been detected in close proximity to these installations with our observation methods. Thus, the potential associations between cetaceans (and other megafauna groups) and human marine structures should be taken into account in any future management of these marine installations. For instance, decommissioning marine oil/gas structures may have significant impacts on the various components of marine ecosystems, including marine mammals (Fowler et al., 2014, 2018; van Elden et al., 2019). This is because some of these structures are likely to play the role of 'protected areas' providing feeding sites for these animals (Todd et al., 2020). Apart from that, the probability that the anthropogenic marine structures may have some negative impacts on marine megafauna is worth investigating in future studies (Todd et al., 2020).

\section{CONCLUSION}

This study provided the first data about the diversity, density, distribution, and ecology of marine mammals occurring in the Saudi waters of the Arabian Gulf. Among the eight species occurring in this region, bottlenose, humpback, and dugongs are the most common. Bottlenose and humpback dolphins appeared to be distributed in all Saudi waters of the Gulf (both nearshore and offshore waters). While small-sized cetaceans (bottlenose, humpback, finless porpoise, and dugongs) were mostly observed in coastal areas, big-sized mammals (Bryde's whales, humpback whales, and killer whales) seem to prefer offshore deep waters. Based on the opportunistic sighting reports and boat-based reports, three coastal areas with the highest occurrence of cetaceans, in particular bottlenose and humpback dolphins, can be defined: Gulf of Slawah, Abu Ali, and Manifa-Safaniya. These three areas are known to host important seagrass meadows acting as foraging and nursery areas for hundreds of fish and shellfish species (Rabaoui et al., 2017). These latter are likely to represent attractive trophic resources for dolphins. Therefore, it can be deduced that any management and conservation plan of dolphins and dugongs should consider the protection of these coastal habitats.

The density estimates and the information on distribution and habitat use obtained in this study are essential for assessing the potential impacts of anthropogenic activities in the western Arabian Gulf. This oil-rich region is characterized by a welldeveloped oil industry in both coastal and offshore waters. These baseline data will provide industry and regulators with the details needed to better manage offshore oil/gas structures and their future decommissioning, as well as to determine potential monitoring and mitigation strategies to minimize impacts on marine mammals. Information on the distribution and density of the eight cetacean species recorded here will be particularly important for future construction and post-construction impact studies. Assuming the protocols are retained in future surveys, these relative density estimates provide a baseline that can be compared with estimates obtained during pre-construction, construction and post-construction activities to assess impacts and changes over time. Baseline estimates can also be used to determine site-specific catch estimates for bycatch authorizations and can be used to inform the timing of construction activities to minimize potential impacts during known periods of marine mammal presence.

The occurrence of dugongs in the Saudi waters is very scarce and seems to be more frequent during the cool season (November-February) in the Gulf of Salwah and Ras Abu Gamis (at the Saudi border with Qatar and United Arab Emirates). The protection of the Arabian Gulf population of dugongs should consider the adoption of a common conservation strategy between these three countries.

\section{DATA AVAILABILITY STATEMENT}

The original contributions presented in the study are included in the article/ Supplementary Material, further inquiries can be directed to the corresponding author/s.

\section{ETHICS STATEMENT}

Ethical review and approval was not required for this animal study, in accordance with the local legislation and institutional requirements.

\section{AUTHOR CONTRIBUTIONS}

LR conceived the work and drafted the manuscript. LR, LY, RR-U, and Y-JL analyzed the data. LR, RM, PPa, JG, RL, PPr, AQ, TH, and MQ contributed to data collection. All authors contributed to the interpretation of the data and to the improvement of the manuscript.

\section{ACKNOWLEDGMENTS}

The authors would like to thank all those who provided mammals' sighting records and contributed to the questionnaire surveys. The authors also grateful to the two reviewers who helped to improve the quality of the manuscript through their valuable and constructive comments and suggestions.

\section{SUPPLEMENTARY MATERIAL}

The Supplementary Material for this article can be found online at: https://www.frontiersin.org/articles/10.3389/fmars.2021. 687445/full\#supplementary-material 


\section{REFERENCES}

Aguirre, A. A., and Tabor, G. M. (2004). Introduction: marine vertebrates as sentinels of marine ecosystem health. EcoHealth 1, 236-238.

Al-Abdulrazzak, D., and Pauly, D. (2017). Reconstructing historical baselines for the Persian/Arabian Gulf Dugong, Dugong dugon (Mammalia: Sirena). Zool. Middle East 63, 95-102. doi: 10.1080/09397140.2017.1315853

Arnould, J. P., Monk, J., Ierodiaconou, D., Hindell, M. A., Semmens, J., Hoskins, A. J., et al. (2015). Use of anthropogenic sea floor structures by Australian fur seals: potential positive ecological impacts of marine industrial development? PLoS One 10:e0130581. doi: 10.1371/journal.pone.0130581

Baldwin, R. M., Collins, M., Van Waerebeek, K., and Minton, G. (2004). The indo-pacific humpback dolphin of the Arabian Region: a status review. Aqua. Mammals 30, 111-124. doi: 10.1578/am.30.1.2004.111

Bonde, R. K., Aguirre, A. A., and Powell, J. (2004). Manatees as sentinels of marine ecosystem health: are they the 2000-pound canaries? EcoHealth 1, 255-262.

Bowen, W. D. (1997). Role of marine mammals in aquatic ecosystems. Mar. Ecol. Prog. Ser. 158, 267-274. doi: 10.3354/meps158267

Buckland, S. T., Anderson, D. R., Burnham, K. P., Laake, J. L., Borchers, D. L., and Thomas, L. (2001). Introduction to Distance Sampling Estimating Abundance of Biological Populations. Oxford: Oxford University Press.

Carpenter, K. E., Krupp, F., Jones, D. A., and Zajonz, U. (1997). The Living Marine Resources of Kuwait, Eastern Saudi Arabia, Bahrain, Qatar, and the United Arab Emirates. FAO Species Identification Guide for Fishery Purposes. Rome: FAO, 293.

Chen, B., Zheng, D., Yang, G., Xu, X., and Zhou, K. (2009). Distribution and conservation of the Indo-Pacific humpback dolphin in China. Integr. Zool. 4, 240-247. doi: 10.1111/j.1749-4877.2009.00160.x

Chen, T., Hung, S. K., Qiu, Y., Jia, X., and Jefferson, T. A. (2010). Distribution, abundance, and individual movements of Indo-Pacific humpback dolphins (Sousa chinensis) in the Pearl River Estuary, China. Mammalia 74, $117-125$.

Cremer, M. J., Barreto, A. S., Silva Hardt, F. A., Tonello Junior, A. J., and Mounayer, R. (2009). Cetacean occurrence near an offshore oil platform in southern Brazil. Biotemas 22, 247-251.

Delefosse, M., Rahbek, M. L., Roesen, L., and Clausen, K. T. (2018). Marine mammal sightings around oil and gas installations in the central North Sea. J. Mar. Biol. Assoc. U.K. 98, 993-1001. doi: 10.1017/s0025315417000406

Díaz López, B. (2020). When personality matters: personality and social structure in wild bottlenose dolphins, Tursiops truncatus. Animal Behav. 163, 73-84. doi: 10.1016/j.anbehav.2020.03.001

Díaz López, B. D., Bunke, M. and Shirai, J. A. B. (2008). Marine aquaculture off Sardinia Island (Italy): ecosystem effects evaluated through a trophic massbalance model. Ecol. Model. 212, 292-303.

Díaz López, B., Grandcourt, E., Methion, S., Das, H., Bugla, I., Al Hameli, M., et al. (2018). The distribution, abundance and group dynamics of Indian Ocean humpback dolphins (Sousa plumbea) in the Emirate of Abu Dhabi (UAE). J. Mar. Biol. Assoc. U.K. 98, 1119-1127. doi: 10.1017/s0025315417001205

Estes, J. A. (1979). Exploitation of marine mammals: r-selection of K-strategists? J. Fish. Res. Bd. Can. 36, 1009-1017. doi: 10.1139/f79-140

Fowler, A. M., Jørgensen, A.-M., Svendsen, J. C., Macreadie, P. I., Jones, D. O., Boon, A. R., et al. (2018). Environmental benefits of leaving offshore infrastructure in the ocean. Front. Ecol. Environ. 16: 571-578.

Fowler, A. M., Macreadie, P. I., Jones, D. O. B., and Booth, D. J. (2014). A multi-criteria decision approach to decommissioning of offshore oil and gas infrastructure. Ocean Coast. Manag. 87, 20-29. doi: 10.1016/j.ocecoaman.2013. 10.019

Frazier, J., Bertram, G. C., and Evans, P. G. H. (1984). "Turtles and marine mammals," in Key Environments: Red Sea, eds A. J. Edwards and S. M. Head (Oxford: Pergamon Press).

Giralt Paradell, O, Díaz López, B., and Methion, S. (2019). Modelling common dolphin (Delphinus delphis) coastal distribution and habitat use: insights for conservation. Ocean Coast Manag. 179:104836

Haugen, J. B., and Papastamatiou, Y. (2019). Observation of a porbeagle shark Lamna nasus aggregation at a North Sea oil platform. J. Fish Biol. 95, 1496-1499. doi: $10.1111 /$ jfb.14149
Hemami, M. R., Ahmadi, M., Sadegh-Saba, M., and Moosavi, S. M. M. (2018). Population estimate and distribution pattern of Indian Ocean humpback dolphin (Sousa plumbea) in an industrialised bay, northwestern Persian Gulf. Ecol. Indicators 89, 631-638. doi: 10.1016/j.ecolind.2018.02.031

Hodgson, A. (2012). "Marine mammals," in Marine Atlas: Western Arabian Gulf, 2nd Edn, eds R. A. Loughland and K. A. Abdulkader (Dhahran: Saudi Aramco).

Jessup, D. A., Miller, M., Ames, J., Harris, M., Kreuder, C., Conrad, P. A., et al. (2004). Southern sea otter as a sentinel of marine ecosystem health. EcoHealth 1, 239-245.

Katona, S., and Whitehead, H. (1988). Are Cetacea ecologically important? Oceanogr. Mar. Biol. Annu. Rev. 26, 553-568.

Laws, R. M. (1984). “Seals," in Antarctic Ecology, ed. R. M. Laws (London: Academic Press), 621-716.

Lindén, O., Jernelöv, A., and Egerup, J. (2004). The Environmental Impacts of the Gulf War 1991. Interim Report IR-04-019. Laxenburg: International Institute for Applied Systems Analysis, 94.

Mackintosh, N. J. (1974). The Psychology of Animal Learning. Cambridge, MA: Academic Press.

McDonald, T., Carlisle, J., and McDonald, A. (2019). Rdistance: Distance-Sampling Analyses for Density and Abundance Estimation. $R$ Package Version 2.1.3. Available online at: https://CRAN.R-project.org/package=Rdistance (accessed January 03, 2019).

McLean, D. L., Partridge, J. C., Bond, T., Birt, M. J., Bornt, K. R., and Langlois, T. J. (2017). Using industry ROV videos to assess fish associations with subsea pipelines. Continent. Shelf Res. 141, 76-97. doi: 10.1016/j.csr.2017.05.006

McLean, D. L., Vaughan, B. I., Malseed, B. E., and Taylor, M. D. (2019). Fish habitat associations on a subsea pipeline within an Australian Marine Park. Mar. Environ. Res. 153:104813. doi: 10.1016/j.marenvres.2019.104813

Miller, L. J., Mackey, A. D., Solangi, M., and Kuczaj, S. A. II (2013). Population abundance and habitat utilization of bottlenose dolphins in the Mississippi Sound. Aqua. Conserv. 23, 145-151. doi: 10.1002/aqc.2278

Mullin, K. D., McDonald, T., Wells, R. S., Balmer, B. C., Speakman, T., Sinclair, C., et al. (2017). Density, abundance, survival, and ranging patterns of common bottlenose dolphins (Tursiops truncatus) in Mississippi Sound following the Deepwater Horizon oil spill. PLoS One 12:e0186265. doi: 10.1371/journal.pone. 0186265

Orr, A. J., Harris, J. D., Hirschberger, K. A., and DeLong, R. L. (2017). Qualitative and Quantitative Assessment of use of Offshore Oil and Gas Platforms by the California Sea Lion (Zalophus californianus). Technical report: U.S. Department of Commerce, NOAA Technical Memorandum NMFS-AFSC-362. Washington, DC: NOAA.

Preen, A. (2004). Distribution, abundance and conservation status of dugongs and dolphins in the southern and western Arabian Gulf. Biol. Conserv. 118, 205-218. doi: 10.1016/j.biocon.2003.08.014

R Core Team (2019). R: A Language and Environment for Statistical Computing. Vienna: R Foundation for Statistical Computing.

Rabaoui, L., Lin, Y.-J., Maneja, R. H., Qurban, M. A., Abdurahiman, P., Premlal, P., et al. (2017). Nursery habitats and life history traits of the green tiger shrimp Penaeus semisulcatus (De Haan, 1844) in the Saudi waters of the Arabian Gulf. Fish. Res. 195, 1-11. doi: 10.1016/j.fishres.2017.06.013

Rabaoui, L., Lin, Y.-J., Qurban, M. A., Maneja, R. H., Franco, J., Joydas, T. V., et al. (2015). Patchwork of oil and gas facilities in Saudi waters of the Arabian Gulf has the potential to enhance local fisheries production. ICES J. Mar. Sci. 72, 2398-2408. doi: 10.1093/icesjms/fsv072

Ray, G. C. (1981). "The role of large organisms”, in Analysis of Marine Ecosystems, ed. A. R. Longhurst (London: Academic Press), 397-413.

Roa-Ureta, R. H. (2015). Stock assessment of the Spanish mackerel (Scomberomorus commerson) in Saudi waters of the Arabian Gulf with generalized depletion models under data-limited conditions. Fish. Res. 171, 68-77. doi: 10.1016/j.fishres.2014.08.014

Russell, D. J. F., Brasseur, S. M. J. M., Thompson, D., Hastie, G. D., Janik, V. M., Aarts, G., et al. (2014). Marine mammals trace anthropogenic structures at sea. Curr. Biol. 24, R638-R639.

Sutaria, D., and Jefferson, T. A. (2004). Records of Indo-Pacific humpback dolphins (Sousa chinensis, Osbeck, 1765) along the coasts of India and Sri Lanka: An Overview. Aqua. Mamm. 30, 125-136. doi: 10.1578/am.30.1.2004.125

Thomas, L., Williams, R., and Sandilands, D. (2007). Designing line transect surveys for complex survey regions. J. Cetacean Res. Manage. 9, 1-13. 
Thompson, P. M., Lusseau, D., Barton, T., Simmons, D., Rusin, J., and Bailey, H. (2010). Assessing the responses of coastal cetaceans to the construction of offshore wind turbines. Mar. Pollut. Bull. 60, 1200-1208. doi: 10.1016/j. marpolbul.2010.03.030

Todd, V. L. G., Lazar, L., Williamson, L. D., Peters, I. T., Hoover, A. L., Cox, S. E., et al. (2020). Underwater visual records of marine megafauna around offshore anthropogenic structures. Front. Mar. Sci. 7:230.

Todd, V. L. G., Pearse, W. D., Tregenza, N. C., and Todd, I. B. (2009). Diel echolocation activity of harbour porpoises (Phocoena phocoena) around North Sea offshore gas installations. ICES J. Mar. Sci. 66, 734-745. doi: 10.1093/ icesjms/fsp035

Todd, V. L. G., Warley, J. C., and Todd, I. B. (2016). Meals on wheels? A decade of megafaunal visual and real-time passive acoustic monitoring detections from on-tow and stationary offshore oil and gas rigs and platforms in the North and Irish Seas. PLoS One 11:25.

van Elden, S., Meeuwig, J. J., Hobbs, R. J., and Hemmi, J. M. (2019). Offshore oil and gas platforms as novel ecosystems: a global perspective. Front. Mar. Sci. 6:548.

Wells, R. S., Rhinehart, H. L., Hansen, L. J., Sweeney, J. C., Townsend, F. I., Stone, R., et al. (2004). Bottlenose dolphins as marine ecosystems sentinels: developing a health monitoring system. EcoHealth 1, 246-254.

Williams, R., and Thomas, L. (2007). Distribution and abundance of marine mammals in the coastal waters of British Columbia, Canada. J. Cetacean Res. Manage. 9, 15-28.
Xu, X., Song, J., Zhang, Z., Li, P., Yang, G., and Zhou, K. (2015). The world's second largest population of humpback dolphins in the waters of Zhanjiang deserves the highest conservation priority. Sci. Rep. 5:8147.

Conflict of Interest: RL, PPr, AQ, and TH are employed by Saudi Aramco (Saudi Arabia).

The remaining authors declare that the research was conducted in the absence of any commercial or financial relationships that could be construed as a potential conflict of interest.

Publisher's Note: All claims expressed in this article are solely those of the authors and do not necessarily represent those of their affiliated organizations, or those of the publisher, the editors and the reviewers. Any product that may be evaluated in this article, or claim that may be made by its manufacturer, is not guaranteed or endorsed by the publisher.

Copyright (c) 2021 Rabaoui, Roa-Ureta, Yacoubi, Lin, Maneja, Joydas, Panickan, Gopalan, Loughland, Prihartato, Qassem, Hikmawan, Diaz Lopez and Qurban. This is an open-access article distributed under the terms of the Creative Commons Attribution License (CC BY). The use, distribution or reproduction in other forums is permitted, provided the original author(s) and the copyright owner(s) are credited and that the original publication in this journal is cited, in accordance with accepted academic practice. No use, distribution or reproduction is permitted which does not comply with these terms. 